\title{
Surprises in scheduled macroeconomic announcements: Why do they move the bond market? ${ }^{*}$
}

\author{
Dieter Hess
}

\author{
Center of Finance and Econometrics, University of Konstanz \\ Fach D 147, D-78457 Konstanz, Germany \\ email: dieter.hess@uni-konstanz.de \\ tel: $+49(0) 7531883164$ \\ fax: $+49(0) 7531883559$
}

\section{Centre for European Economic Research (ZEW) \\ Discussion Paper No. 00-61 \\ October 2000}

Keywords: Macroeconomic news; scheduled announcements; public information; price formation; Treasury bonds; futures market.

JEL classification: E44, G14

\footnotetext{
${ }^{*}$ For valuable comments I am grateful to Jan Beran, Angelika Eymann, Yuanhua Feng, Bernd Fitzenberger, Günter Franke, Frank Gerhard, Nikolaus Hautsch, Joachim Inkmann, Stefan Klotz, Michael Lechner, Bina Lehmann, Erik Lüders, Jürgen Meckl, Christian Meurer, Winfried Pohlmeier, Michael Schröder, Jack Wahl, and Peter Winker. This paper has also benefited from participants' comments at the Seventh Annual Meeting of the German Finance Association (DGF) and workshops at the Universities of Konstanz, Mannheim, and St. Gallen. Data on analysts' forecasts were generously provided by Standard \& Poors Global Markets. Research support by the Centre for European Economic Research (ZEW) and financial support by the Deutsche Forschungsgemeinschaft (DFG, Project HE 3810/1) is gratefully acknowledged.
} 


\section{Introduction}

It is well known that information arrival has an impact on prices volatility, and trading volume in financial markets (see e.g., Goodhart and O'Hara 1997). Scheduled macroeconomic announcements, such as monthly employment figures, consumer prices, or building permits, stand out from the steady flow of information. ${ }^{1}$ Several studies (e.g. Fleming and Remolona 1997) show that these releases have a very distinct impact on prices. While most of these studies try to find out which releases are significant, considerably less effort has been devoted to the question what makes some releases so important in contrast to others that seem to attract no attention. Papers addressing this question emphasize the content of releases. For example, Edison (1996) discriminates between news related to unexpected inflation and those related to unexpected changes in economic activity. Investigating intraday T-bond futures price responses to surprises in scheduled macroeconomic releases, this paper presents evidence that the type of information is relevant. More specifically, the results suggest that the sequence of releases within a given content category helps to explain their relative importance. In other words, if market participants have already observed some figures on which they can base their assessment of a particular aspect of the economy, then the additional information of another related report should be small, and thus, its impact on prices.

Every month, a variety of U.S. macroeconomic figures are released according to a fixed schedule. The impact of these scheduled releases on the volatility of financial

\footnotetext{
${ }^{1} \mathrm{~A}$ variety of measures for information arrival has been employed in the literature, for example, Mitchell and Mulherin (1994) use the daily number of news announcements reported by Dow Jones \& Company, Chang and Taylor (1996) a keyword count in Reuters headlines.
} 
markets is underlined, for example, by the findings of Fleming and Remolona (1997) that out of the 25 largest intraday price changes in the U.S. treasuries market all but one occurred after such an announcement. This is confirmed by Bollerslev, Cai, and Song (2000) for T-bond futures. Constructing dummy variables from the schedule of macroeconomic releases, Ederington and Lee (1993), Crain and Lee (1995), and others, find that quite a number of releases have a significant impact on volatility in the bond and foreign exchange market. Using robust tests, Franke and Hess (2000) find an even larger spectrum of releases to be significant. The increase in volatility seems to be short-lived, suggesting that the increased uncertainty due to these announcements decreases rapidly to a more normal level (see e.g., Fleming and Remolona 1999a). However, some other studies indicate (e.g. Andersen and Bollerslev 1997) that the increase in volatility after certain announcements may well extend over one trading day.

Volatility studies do not account for surprises in released reports. In general, the impact of the mere existence of an announcement is investigated using dummy variables. In contrast, another branch of the literature investigates the impact of surprises in announcements on the level of prices, mainly in bond and foreign exchange markets. Usually, these studies measure the magnitude of surprises employing survey data on analysts' forecasts for certain headline figures contained in macroeconomic reports. Early studies focus on a small number of releases investigating their impact on daily returns. Berkman (1978), Urich and Wachtel (1981, 1984), and others investigates money growth announcements, Cook and Korn (1991) and Prag (1994), for example, focus on employment reports. Since in the early 1980s the Federal Reserve deemphasized monetary aggregates to guide its policy actions, 
Dwyer and Hafer (1989) among others, investigate whether the Fed's focus on current economic conditions leads to significant interest rate changes after surprises in various macroeconomic reports. Interestingly, they find that the impact of money growth announcements diminishes in the mid-1980s. Consequently, other studies, such as Hardouvelis (1988) and Edison (1996), find a growing influence of employment figures, releases of consumer or producer prices, durable goods orders and retail sales. While these studies examine daily interest rate changes, Becker, Finnerty, and Kopecky (1996) and Fleming and Remolona (1997, 1999b) focus on narrow intraday windows around the announcements in order to separate the impact of scheduled announcements from other not explicitly observed news. As a consequence, Fleming and Remolona find more releases that have a significant impact on prices in the Treasury market.

So far, Fleming and Remolona (1997) use the most comprehensive set of releases, investigating price reactions to surprises in 19 headline figures. But they only use one year of data. While Fleming and Remolona (1999b) extend the sample period they drop quite a few releases focusing on 8:30 releases exclusively. Despite an overlapping sample period, both studies arrive at contradicting results. For example, in contrast to the first study, the second finds significant bond price reactions to surprises in durable goods orders, retail sales, and in leading indicators. Hence, the question which releases have a significant impact on the level of prices in the bond market remains open for debate. Therefore, this study re-evaluates this question analyzing a more comprehensive set of announcement data, i.e. 24 headline figures. In order to avoid small sample problems, we use an extended and updated sample of intraday data, i.e. we investigate tick-by-tick T-bond futures prices from 1994 to 1999. 
Moreover, this paper extends the previous literature by a content analysis of reports. Instead of restricting the analysis to the question which releases produce significant coefficients in a regression framework, the information content of releases and the structure of the announcement cycle is investigated more closely. This allows to derive and test some hypotheses concerning the relative importance of releases. In particular, I assume that market participants watch several aspects in macroeconomic reports in order to obtain a picture of the state of the economy. This leads to a classification of news releases on the basis of the type of information they provide. Then the main hypothesis states that the value of the information contained in a release decreases with the number of previously released figures falling into the same content category. For example, the demand in the housing sector for a given month may be derived from the reports on housing starts, new home sales and construction spending. But their price impact should decrease as one after another is announced, since the additional information a report provides about the strength of demand in that sector becomes smaller and smaller.

The remainder of the paper is organized as follows. The next section describes the structure of the macroeconomic release cycle and the content of major releases. Moreover, some hypotheses concerning the relative importance of reports are presented. In section 3 these hypotheses are tested on the basis of a system of equations describing the impact of surprises in headline figures on prices. Section 4 concludes. 


\section{The impact of new information on prices}

\section{$2.1 \quad$ T-Bond futures price changes}

In this study, we investigate the price reaction of U.S. Treasury bond futures to news releases. This contract is listed at the Chicago Board of Trade (CBT) and calls for delivery of a T-bond with at least 15 years to maturity. Issues being deliverable typically have a duration around 8 to 12 years. In this study we focus on the front month futures contract, i.e. the contract expiring within the next $3 \frac{1}{2}$ months.

In order to analyze the impact of news on T-bond futures prices, let us first consider the simple example of a parallel upwards shift of the whole term-structure. Such a movement of interest rates will have two opposite effects on futures prices: ${ }^{2}$ Bond prices decline and thus the futures price. On the other hand, it renders the short seller's financing strategy of such a contract more costly and thus leads to an increase in the futures price. Using duration to approximate the relative impact, the futures price change induced by bond price movements outweighs the cost-of-carry impact by a factor of at least 25. Differences in the pricing of forward and futures prices are neglected here. Futures prices may differ from simple forward contracts due to the embedded options ${ }^{3}$ as well as the stochastic nature of margin $\operatorname{costs}^{4}$. However, these valuation differences should be fairly stable over the very short intraday intervals investigated here. Therefore, the major part of a futures price change is driven by price changes of the underlying long-term bonds.

Let $\Delta P_{i}$ denote the change of the futures price in a narrow time interval around $t_{i}$.

\footnotetext{
${ }^{2}$ For details see e.g., Jarrow (1996).

${ }^{3}$ See e.g., Hemler (1990)

${ }^{4}$ See e.g., Cox, Ingersoll, and Ross (1981)
} 
More precisely, this is the difference between the last trading price observed before $t_{i}$ and the last price observed within the interval $\left[t_{i}, t_{i}+\Delta t\right)$, where $\Delta t$ equals five minutes. We assume that this price change can be written as a linear function of distinct pieces of news arriving during this period. A part of this information flow is observed in this study. I employ data of non-revised headline figures of scheduled macroeconomic reports, i.e. figures that summarize major parts of the information contained in a release. Let $A_{j}$ denote the announced value of the $j$ th headline figure. $D_{j, i}$ is a dummy variable equal to one if $A_{j}$ arrives during the time interval $\left[t_{i}, t_{i}+\Delta t\right)$. In addition, I also observe market participants' forecasts of these figures, denoted by $F_{i}$. Like in previous studies, the median forecast of analysts surveyed by Standard \& Poors, Global Markets Division (also known as MMS) is used. The future price change may then be written as a function of surprises in headline figures, i.e. $A_{j}-F_{j}$,

$$
\Delta P_{i}=\sum_{j} \alpha_{j}\left(A_{j}-F_{j}\right) D_{j, i}+\varepsilon_{i}
$$

Any other information arriving between $t_{i}$ and $t_{i}+\Delta t$ which might surprise market participants is caught by the error term $\varepsilon_{i}$ in (1). Since we investigate price reactions in very narrow time windows around announcements, the impact of this error should be small and have zero expectations.

We investigate T-Bond futures price reactions to announcements being made at three distinct release times, i.e. 8:30, 9:15, 10:00 a.m. EST. According to the well known efficient market hypothesis we would expect that the impact of a surprise is incorporated rapidly in prices, especially since we are looking at widely anticipated headline figures and the price response of one of most actively traded futures contracts. ${ }^{5}$ For example, it would be rather astonishing to find that a surprise in an

\footnotetext{
${ }^{5}$ Information processing in the open outcry system of the CBT should be very efficient. For a
} 
8:30 headline still has an impact on five-minute price changes around 9:15. Since the remainder of this paper analyzes the value of information contained in releases, it is rather essential that we look at a market that processes information efficiently. Therefore, we will have to test the following hypothesis first.

\section{H1: Immediate response}

If markets are processing information efficiently prices should adjust immediately to surprises in releases.

\subsection{The macroeconomic release cycle}

Each month numerous macroeconomic reports are released providing insights on the state of the U.S. economy from a whole range of different perspectives. ${ }^{6}$ Some reports are compiled by Government agencies, such as the Bureau of Labor Statistics, and some by private sector institutions, for example the National Association of Purchasing Managers. Some are released on a weekly basis, but the bulk of statistics is announced on a monthly or quarterly schedule. In this study we focus on reports which are released within the floor trading hours of the CBT T-bond futures. Table 1 in the appendix lists these reports along with the major headline figures. To gain a better understanding of the relative importance of individual reports some classification schemes are introduced in the remainder of this section.

discussion of information diffusion in electronic and floor trading systems see, for example, Franke and Hess (2000).

${ }^{6}$ For a detailed description of individual releases and headline figures see, for example, Frumkin (1994), Rogers (1994), or Niemira and Zukowski (1998). 


\subsubsection{Differentiating reports by the type of information}

Unexpected parts in macroeconomic news releases may lead agents to revise their expectations of nominal interest rates, due to either higher future inflation rates or higher real rates. In order to explain the significant impact of some releases on interest rates, previous studies have tried to identify whether an announcement provides information that might alter market participants expectations of real rates or inflation rates. ${ }^{7}$ This is re-stated by classification $\mathrm{C} 1$ :

\section{C1: Major content classes}

Since nominal interest rates can be decomposed into real interest rates and inflation expectations non-anticipated information suggesting either a change in real interest rates and/or futures inflation rates should have an impact on T-Bond futures prices.

Following Edison (1996), we categorize headline figures in macroeconomic releases according to their content into two broad groups: figures that provide inflation measurements (C3), and others that hint to higher levels of real activity (C2). Note that in contrast to studies like Hardouvelis (1988) or Dornau and Schröder (2000), the purpose of this classification is not to find out which model market participants might have in mind or to assess the empirical relevance of different models. The sole purpose is to identify common characteristics in releases.

\footnotetext{
${ }^{7}$ Other studies, for example Dwyer and Hafer (1989), investigate also monetary phenomenons. We refrain from doing so, since money supply figures are released at 16:30 EST, and thus not within the time span covered by our intraday floor trading data set, i.e. 8:20-14:00 EST. Moreover, since weekly money growth figures are very volatile they provide noisy signals at best. This may be one reason why the financial press rarely discusses weekly money growth figures. If at all, monthly or quarterly averages are highlighted.
} 
Usually, we may assume that higher levels of real economic activity are associated with higher real interest rates. If increasing economic activity is coupled with increasing investments, and thus, with a higher demand for capital, interest rates should rise, given a finite elasticity of capital supply. However, information about higher economic activity might also alter agents' expectations of future inflation rates. Inflation might be spurred by an overheating economy. Hence, an unexpected increase in real activity could drive interest rates up through higher real rates and/or higher inflation expectations. Figures falling into this category are detailed in classification scheme C2. Since there are quite a number of headline figures that provide information about economic activity and since they are rather heterogeneous, we distinguish three subcategories.

The first contains headline figures that provide some evidence about the overall production level. This is certainly true for the industrial production figure $\left(I P_{1}\right)$. Another example is the index of the National Association of Purchasing Managers $(N A P M)$. This composite index is based on a questionnaire covering several areas of business activity, among them the current level of production, new orders from customers, and employment in the manufacturing sector. In addition, figures on orders could give some clues. For example, durable goods orders ( $D G O)$ measure orders, shipments, and unfilled orders placed with U.S. manufacturers for goods with a life expectancy of at least three years. Factory orders $\left(F I_{2}\right)$ include non-durable goods as well. 


\section{C2: Economic activity}

Surprises in releases suggesting a higher than expected level of economic activity should lead to rising nominal interest rates due to higher real rates and/or higher inflation expectations. The level of economic activity may be inferred from the following three groups of headline figures:

(a) Overall production level: $N A P M_{1}, I P_{1}, D G O_{1}, G D P_{1}, L I_{1}, F I_{2}$.

(b) Demand for consumption goods: $C C_{1}, R S_{1}, P I_{2}, L I_{1}$.

(c) Demand in housing sector: $H S_{1}, N H S_{1}, L I_{1}, C S_{1}$.

The second subcategory in $\mathrm{C} 2$ contains specific information about consumer demand. Data on this aspect are provided by the retail sales report $(R S)$ and by the personal consumption expenditures figure $\left(P I_{2}\right)$. In addition, the consumer confidence report $(C C)$ may allow some conclusions about the future spending behavior of consumers.

A third group of related headline figures contain information about demand in the housing sector: The housing starts report measures the total number of residential units on which construction has begun in a given month $(H S)$. Another figure is provided by the new home sales report disclosing unit sales of single family homes $(N H S)$. Since it also includes data on average prices this report provides market participants with a picture of the volume of residential construction activity. Moreover, the construction spending report $(C S)$ measures total construction put in place divided into residential, commercial, and public expenditures.

The second broad content category (C3) relates to measurements of inflation. However, there is not just one measure of inflation. Throughout this paper, we assume that price increases at the production level indicate inflation just as well as increases 
in consumer prices do. Instead, classification C3 differentiates between three groups of figures: (a) figures that provide a measure of past price changes of finished goods, (b) early inflation indicators derived from observed price changes of input factors, and (c) shortages of production factors which might translate into price pressures of input factors.

The first subcategory in C3 contains figures measuring past inflation, however related to different measurement concepts. Among them are the monthly consumer and producer price indices. Previous studies use the overall consumer and producer prices indices. Instead, we focus on the less volatile core inflation numbers which exclude food and energy $\left(\mathrm{PPI}_{2}, \mathrm{CPI}_{2}\right)$. Another inflation measure is provided by the price deflator contained in the quarterly GDP report $\left(G D P_{2}\right)$.

The second subcategory contains observed price changes at early stages of the production process. Several reports contain detail information that allow this kind of inference. For example, price increases of raw material and unfinished goods which are released along with the PPI index. Unfortunately, we observe only two headline figures falling into this subcategory for which analyst forecasts are available. These are labor costs $(E C I)$ and the productivity figure $(P C)$. Both, higher than expected wages and lower productivity, might suggest that inflation pressures are building up, especially if wages rise faster than productivity.

The third subcategory of inflation harbingers is summarized under the headline of shortage of production factors in C3. These are figures which do not report already observed price changes but provide indications of bottlenecks in the production process which could lead to price increases. For example, a stretched capacity utilization $\left(I P_{2}\right)$ or low inventories $\left(B I_{1}, F I_{1}\right)$ may point to supply bottlenecks. Furthermore, 
if in a tight labor market employees have more bargaining power, a lower than expected unemployment rate $\left(E_{2}\right)$ may foreshadow higher wages and, thus, inflation pressures.

\section{C3: Inflation expectations}

Surprises in releases suggesting a change of future inflation rates should have a significant impact on T-bond futures prices. Inflation expectations of market participants may be altered by surprises in reports falling into the following three groups:

(a) Measures of past price changes: $P P I_{2}, C P I_{2}, G D P_{2}$.

(b) Early inflation indicators: $E C I_{1}, P C_{1}$.

(c) Shortage of production factor: $N A P M_{1}, E_{2}, I P_{2}, F I_{1}, B I_{1}$.

\subsection{Determinants of the relative importance}

\subsubsection{Sequence and timeliness of releases}

Over the course of a month each release adds a piece of information on the strength of the economy. After a while, when several figures have added a variety of different aspects, market participants should have a relative clear picture. Therefore, it seems reasonable to assume that the information content of further releases for a given reference period (i.e. the month or quarter the reports are referring to) diminishes as more and more reports are released. More precisely, in $\mathrm{H} 2$ we postulate that a surprise contained in a release has a high impact on market participants' assessment of the state of the economy as long as they have relatively few other figures at hand to balance its impression. 


\section{H2: Sequence}

The impact of a release on T-Bond futures prices depends on the number of previously released reports.

An alternative explanation is provided by Fleming and Remolona (1997). Observing that the three most recently available government reports $(C P I, P P I$, and $R S)$ have the highest impact on five year T-note prices they conclude that the time between the end of the reporting period and the announcement helps to explain the impact of a release. This conclusion is re-stated in hypothesis H3:

\section{H3: Timeliness}

The impact of a release on T-Bond futures prices depends on the time between the announcement of a report and the end of the reference period.

Fleming and Remolona (1997) also observe that the two private sector reports, $C C$ and $N A P M$, which are released a few days in advance of non-government have a lower impact. This contradicts H3, but also H2. Although the impact of surprises in reports may not decrease linearly with the time elapsed since the end of the reference month, we would nevertheless expect that reports with a time lag of more than a month should have almost no impact since reports for the following calendar month are already available. This would imply that $L I$ and other reports released later on, have no impact at all (see figure 1 in the appendix).

Figure 1 provides an illustration of the timeliness of releases according to H3. It displays the number of days between the release and the end of the reporting period. 
For monthly (quarterly) releases this is the end of the calendar month (quarter). The report on consumer confidence provides the first evidence for a given month. It is already released before the end of the reference period, typically on the last Tuesday of a month. It is followed by the NAPM index which is usually announced on the first business day after the end of the reporting period, and the employment report on the first Friday. The early availability of these reports may be attributed to the fact that they are based on surveys which are conducted in the first half of the reference month. In figure 1 the median number of calendar days relative to the end of the reference month is indicated by a square. From the range between the minimum and maximum number of days (solid lines) it becomes clear that the sequence of releases is not the same for each month. For example, normally $N A P M$ is released well in advance of the employment report $(E)$, but occasionally they may be released at the same day. Then, however, employment comes out at 8:30 EST and NAPM at 10:00. In contrast, the sequence of $P P I$ and $C P I$ does not change. $P P I$ and $C P I$ may be released in the same week, but PPI always comes first.

\subsubsection{Type of information}

In section 2.2.1 it has been argued that the relative importance of reports depends only on the type of information they disclose. The content of releases has been classified into two broad categories, inflation measures and economic activity. Within these categories the figures highlight various aspects of inflation and economic strength.

In contrast, the hypotheses presented in section 2.3.1, H2 and H3, argue that the additional information of a report diminishes with the number of already available figures and the elapsed time, ignoring any differences in the contents of the re- 
ports. This would imply that the state variable describing the economy is rather one-dimensional. Instead, it seems more reasonable to assume that market participants consider various aspects of inflation and economic strength to be relevant in order to determine the equilibrium long-term interest rate. Then, a formulation of H2 (and H3) that accounts for the differences in the content of releases seems more appropriate. Therefore, in H4 it is hypothesized that the additional information provided by a report for a given month diminishes with the number of already released reports providing a similar content. In this case we would expect, for example, that the impact of the subsequently released reports of measures of past price changes, $P P I, C P I$, and $G D P_{2}$, would decrease in this order.

\section{H4: Sequence within content classes}

If major components of a release are already known or may be forecasted from other previously released figures, the impact of such a release should be relatively small. Thus, the impact of a report should decrease with the number of previously released reports providing a similar content.

One argument in favor of this hypothesis comes from the fact that certain figures repeat to some extent information contained in previously released reports. A rather outdated figure in this sense is the factory orders number $\left(F I_{2}\right)$ since an earlier estimate can be derived from both, the report on durable good orders covering over $50 \%$ of total factory orders, and the new orders component in the NAPM report. Even worse, the NAPM report for the subsequent month is already available when FI comes out. An even better example is the Leading Indicator Index which is composed of 10 different figures, among them the average workweek contained in 
the previously released employment report, the average initial state unemployment insurance claims from the weekly report on initial unemployment claims, the vendor performance component of the NAPM report, the building permits from the report on housing starts, the weekly money supply figure, etc. All of these are already available at the time of the release. So, little to no price movements should result from its announcement.

\section{Empirical results}

\subsection{Data description}

We investigate surprises in 24 headlines contained in 19 different U.S. macroeconomic reports over a 6 year period, i.e. January 1994 to December 1999. In this study, we focus on monthly and quarterly reports scheduled during the major trading of TBond futures at the Chicago Board of Trade, i.e. at either 8:30 a.m., 9:15 a.m., or 10:30 a.m. Due to certain lock-up conditions, described for example in Fleming and Remolona (1997), reports are released precisely according to the schedule. ${ }^{8}$ However, a major disruption of the news flow occurred in December 1995 and January 1996 caused by a temporary shutdown of several federal agencies due to a federal budget dispute. Since the whole forecasting process might have been affected, we exclude all observations from December 1995 through February 1996 from our analysis.

Consensus forecasts, i.e. median analysts' forecasts, on headline figures in reports were generously provided by Standard \& Poors Global Markets (MMS) for the pe-

\footnotetext{
${ }^{8}$ Fleming and Remolona (1999b) cite two exceptions of this rule. These are two occurrences of inadvertently early released reports, i.e. the November 1998 employment report and the January 1999 PPI report. Nevertheless, strict lockup conditions normally prevent a leakage of information before the official release time (see e.g., Fleming and Remolona 1999)
} 
riod 1995-1999. Earlier forecasts as well as actual outcomes were obtained from several print sources, especially the Wall Street Journal, Barron's, Financial Times, and Business Week. Announcement surprises are calculated subtracting consensus forecasts from the actual outcomes. Note that we do not use the final revised figures as they are available from statistical agencies today, but rather the original, unrevised data available to market participants at the time of the release. ${ }^{9}$ Then, for each headline figure standardized surprises are computed dividing surprises by the mean absolute value of announcements.

The impact of macroeconomic news on the T-Bond futures trading at the Chicago Board of Trade is investigated using intraday data provided by the Futures Industry Institute. This is a so-called tick-by-tick data set containing a time-stamped record whenever a price change is observed. Transaction volumes are not observed. The data set covers the period January 1994 to December 1999. These data usually cover the period from 8:20 to 15:00 EST. We study price changes over five minute intervals around 8:30, 9:15, and 10:00 releases. For example, for 8:30 releases the last price recorded before 8:30 and the last price before 8:35 are used.

\subsection{Estimation of the impact of surprises on price changes}

In order to estimate the response of prices to surprises in news releases, we estimate (1) as a system of three equations, one for each release time. For notational conve-

\footnotetext{
${ }^{9}$ Many macroeconomic figures are subject to several revisions afterwards. For example, the initially reported unemployment rate is revised twice in the subsequent two months. In addition, the data are revised every January for the previous five years. Moreover, major revisions are made occasionally. In 1994, for example, major changes to the Current Population Survey were introduced (see e.g., Bureau of Labor Statistics 1996). This ongoing revision process makes it impossible to calculate actual surprises at a time from the usually available economic time series which contain revised figures.
} 
nience. Ignoring the trading day index, the five minute price change around 8:30, 9:15, and 10:00 releases are denoted as $\Delta P_{8: 30}, \Delta P_{9: 15}$, and $\Delta P_{10: 00}$, respectively.

$$
\begin{aligned}
& \Delta P_{8: 30}=\kappa_{1}+\alpha_{1} S_{E_{1}}+\cdots+\alpha_{15} S_{T R D_{1}}+\varepsilon_{1} \\
& \Delta P_{9: 15}=\kappa_{2}+\beta_{1} S_{E_{1}}+\cdots+\beta_{15} S_{T R D_{1}}+\alpha_{16} S_{I P_{1}}+\alpha_{17} S_{I P_{2}}+\varepsilon_{2} \\
& \Delta P_{10: 00}=\kappa_{3}+\gamma_{1} S_{E_{1}}+\cdots+\gamma_{15} S_{T R D_{1}}+\alpha_{16} S_{I P_{1}}+\alpha_{17} S_{I P_{2}}+\alpha_{18} S_{C C_{1}}+\cdots+\varepsilon_{3}
\end{aligned}
$$

Here, $S_{(\cdot)}$ denotes standardized surprises. For example, $S_{E_{1}}$ denotes the surprise in headline figure $E_{1}$. These variables are zero, if no announcement of a certain release is made at a given day. Note, that we estimate the signed price response to surprises according to the hypothesized T-bond future reaction in table 2. For example, it is hypothesized that T-bond futures prices should fall if the announced non-farm payroll figure $\left(A_{E_{1}}\right)$ is higher than its forecast $\left(F_{E_{1}}\right)$ whereas prices should rise in response to an unexpectedly high unemployment rate $\left(A_{E_{2}}>F_{E_{2}}\right)$. Therefore, we define $S_{E_{1}}=-\left(A_{E_{1}}-F_{E_{1}}\right)$ while $S_{E_{2}}=\left(A_{E_{2}}-F_{E_{2}}\right)$. Then, a positive $S_{(\cdot)}$ should be "good news" for futures prices.

In each equation, the five minute price change is regressed on surprises occurring within the corresponding time interval, and in addition, on surprises occurring earlier at a given day. ${ }^{10}$ The $\alpha_{i}$ coefficients capture the immediate price impact of a release, i.e. the price change occurring in the five minute interval around the announcement. Thus, for the whole set of hypothesized immediate price reactions to be correct all the $\alpha_{i} \mathrm{~s}$ must be positive. The $\beta_{i} \mathrm{~s}\left(\gamma_{i} \mathrm{~s}\right)$ capture the impact of headlines being released

\footnotetext{
${ }^{10}$ The announcement time for two reports (i.e. $L I$ and $B I$ ) changes from 8:30 to 10:00 within our sample. Thus, we have to account for the immediate impact of these releases in two equations. If they are released at 8:30, we estimate an $\alpha_{i}$ in the 8:30 equation, otherwise in the 10:00 equation. However, we restrict the corresponding coefficients to be the same in both equations, since there is no reason to assume that the impact of these releases changes due to an alteration of the release time.
} 
45 (90) minutes earlier at a given day. According to the well known efficient market hypothesis we would expect that the impact of a surprise is incorporated rapidly in prices, and thus, the $\beta_{i}$ s and $\gamma_{i}$ s should not be significantly different from zero. This is stated by $\mathrm{H} 1$, given above.

The system of the three equations is estimated by a seemingly unrelated regression (SUR). Generalized least squares estimates are used in order to account for heteroscedasticity across trading days and contemporaneous correlation in the errors across equations. The employed estimation technique yields results that are asymptotically efficient. If the error terms in the equations are uncorrelated, i.e. $\operatorname{cov}\left(\varepsilon_{i}, \varepsilon_{j}\right)=0, \forall i \neq j$, then a separate least squares estimation of the equations yields efficient parameter estimates, assuming well behaved data (see e.g., Dwivedi and Srivastava 1978). The correlation of single equations residuals estimated with least squares is indeed small (Newey West correlation estimates are: $\rho_{\varepsilon_{1}, \varepsilon_{2}}=0.007$, $\rho_{\varepsilon_{2}, \varepsilon_{3}}=-0.062$, and $\rho_{\varepsilon_{1}, \varepsilon_{3}}=0.032$ ). But since $\rho_{\varepsilon_{2}, \varepsilon_{3}}$ is significantly different from zero at the $10 \%$ level, it cannot be taken for granted that the equations are actually unrelated. This is confirmed by a test on the diagonality of the variance-covariance matrix of the first-stage residuals (see e.g., Baltagi 1999, Ch. 10). The value of this $\chi_{3}^{2}$ distributed test-statistic is 7.47 with a p-value of .058. Therefore, a SUR estimation seems to be more appropriate, although the efficiency gains may be small due to the low correlation of first stage residuals. However, efficiency gains are to be expected from the fact that we impose restrictions across equations.

Parameter estimates are provided in table 3. The $\alpha_{i} \mathrm{~s}$ are printed in bold. As outlined above, only positive $\alpha_{i}$ s are in line with the hypothesized immediate price response. Interestingly, with only two exceptions the signs of the significant $\alpha_{i}$ s are positive. 
The exceptions are $P I_{2}$ and $C S_{1}$. However, the impact of a surprise in these two headline figures is small.

Note that the right hand variables in table 3 are sorted according to the median report time lag (see figure 1). Thus, the ordering reflects the release sequence of the reports.

\subsection{Test of hypotheses}

If markets process new information efficiently the $\beta_{i}$ 's and $\gamma_{i}$ 's should be zero. Indeed, only 5 out of $32 \beta_{i}$ s and $\gamma_{i}$ s are significantly different from zero. Thus, there is at best little evidence that markets are inefficient in the sense that prices adjust slowly to surprises in headline news. In contrast, 18 out of the $24 \alpha_{i}$ s are significant, 15 of them at the $1 \%$ level. This provides some preliminary evidence in favor of $\mathrm{H} 1$. In order to obtain a formal test whether certain groups of parameters are significant, a second estimation step is performed in which we impose certain restraints on the parameters estimated in the first stage. For example, to test whether the $\beta_{i}$ s are redundant, we impose the restrictions $\beta_{i}=\beta^{*}, \forall i=1, \ldots, 17$. Given that these restrictions hold we can test whether $\beta^{*}$ is different from zero, and thus, test H1. Taking into account the variance-covariance of parameters estimated in the first stage an asymptotically consistent and efficient estimates of $\beta^{*}$ can be obtained by means of asymptotic least squares (see e.g., Gourieroux and Monfort 1995, Ch. 9). Results of this estimation are given in table 4 . Each line represents a separate asymptotic least squares estimation in which one group of parameters is restricted. Estimation (2) and (3) in table 4 supports the notion that T-Bond futures markets are efficient. The corresponding $\chi^{2}$ tests cannot reject the hypothesis that the restrictions hold. Moreover, the estimated 
coefficients, $\beta^{*}$ and $\gamma^{*}$, are not significantly different from zero. This means after 45 (as well as 90) minutes we do not find a significant impact. Thus, we are not able to reject $\mathrm{H} 1$. Interestingly, the restriction that we could use one $\alpha^{*}$ to model the immediate impact of the various headline figures is strongly rejected. Although the estimated $\alpha^{*}$ is significantly different from zero, the rejection of the imposed restrictions indicates that the impact of surprises differs across the investigated set of headline figures. This may be taken as some preliminary support of our notion that the value of information is rather heterogeneous across releases.

In order to obtain a better understanding of the immediate impact of different types of information, we test whether the content categories introduced in classification $\mathrm{C} 2$ and $\mathrm{C} 3$ are informative in the sense that T-bond futures prices are sensitive to surprises in these releases. We test the informativeness of the six groups of headlines news by imposing the restriction that all the $\alpha_{i}$ coefficients falling into a certain category are zero. Table 5 reports Wald tests on these linear restrictions. The tests are based on the coefficient variance-covariance matrix estimated by the previously described SUR model. These statistics are $\chi^{2}(\nu)$ distributed with $\nu$ denoting the number of zero restrictions imposed on estimated coefficients (see e.g., Greene 1993). Interestingly, we would have to reject a hypothesis stating that a certain content category is uninformative for all of the six categories, for five at the $1 \%$ level and for one at the $10 \%$ level. Thus, all of the content categories seem to provide useful information for T-Bond traders.

Hypothesis H3 states that the timeliness of releases determines its impact on prices, in contrast $\mathrm{H} 2$ emphasizes the sequence of reports. Some preliminary evidence is gained from a comparison of estimated coefficients. Interestingly, all but one of the 
reports being released within one month after the end of the reporting period, i.e. $C C$ to $N H S$, are significant, mostly at the $1 \%$ level. In contrast, out of the remaining seven headline figures which are typically released in the second month only two are significant. This may be taken as preliminary evidence in favor of a somewhat loose interpretation of hypothesis H3. On the other hand, the first to releases (i.e. $C C$ and $N A P M)$ have a significantly lower impact than the third $\left(E_{1}\right)$, as compared by a one-sided t-test on the difference of coefficients. ${ }^{11}$ Moreover, from both hypotheses we would expect that the last reports in the release cycle have no impact. Again, a Wald test is used to investigate whether the coefficients of those releases which come out with a time lag of more than one month are zero. These are the releases $L I$ to $T R D$. The resulting test statistic is given in table 5, last line. Although only two out of the seven headline figures in this group are significant, we have to reject the hypothesis that their impact as a group is zero. So, these tests provide little if any evidence in favor of $\mathrm{H} 3$ and $\mathrm{H} 2$.

In contrast to $\mathrm{H} 2$ which focuses on the mere sequence of releases and neglects content, hypothesis H4 states that the sequence within content categories is important. Therefore, we investigate whether the impact of releases decreases as more and more reports with a similar content become available. Precisely, we test whether the impact of subsequently released reports within a given content category decreases. We compare the difference of coefficients pairwise by one-sided t-tests. If the impact of reports decreases strictly within a content group, we should find for each pair of successive reports that the difference between consecutive coefficients is significantly positive. However, we do not find this very strong result in any content category.

\footnotetext{
${ }^{11}$ For details see table 6 in the appendix.
} 
Thus the impact is not strictly decaying. Nevertheless, we find strong evidence of a decreasing impact of coefficients comparing the first two headlines with those being released later. Table 6 displays the results of pairwise comparisons of the first and the second headline figure in a given content category with all subsequently released headlines of the same category. For two of these categories, i.e. "overall production level" and "shortage in production factors" the first headline figure has a significantly higher impact than all other figures. For two other categories, "demand for consumption goods" and "demand in the housing sector", we find that the second figure has the strongest impact. The group "early inflation indicators" has only two members. Although the results are in line with our hypothesis this may not be counted as hard evidence. So, there remains only one category for which we do not find a decreasing impact of subsequent releases, i.e. "measures of price changes". However, this does not provide any evidence against hypothesis $\mathrm{H} 4$ since the impact of subsequent releases is not significantly increasing. Overall, the t-tests presented in table 6 support hypothesis $\mathrm{H} 4$.

\section{Summary and conclusions}

T-bond futures prices like bond prices are driven mainly by market participants expectations of real interest rates and future inflation rates. Therefore, the set of headline figures in scheduled macroeconomic releases is divided into two broad content categories, news related to inflation expectations and news related to economic activity, and then again into three finer subcategories. For example, inflation related news are differentiated with respect to their impact on official inflation statistics, i.e. measurements of past price changes in finished goods, observed price changes 
further down in the production channel, and indications of price pressures from a shortage in production factors. Interestingly, nearly all of the significant coefficients capturing T-bond futures reactions to surprises show the correct sign, i.e. the direction of price change is as hypothesized on the basis of the introduced information classification. Moreover, for all of the six categories the hypothesis that surprises in the announcements of corresponding figures have no impact on T-bond prices has to be rejected.

Investigating the sequence of releases without differentiating for content, at best some week evidence is obtained that the sequence or the timeliness of reports matters (hypotheses $\mathrm{H} 2$ and $\mathrm{H} 3$ ). On the one hand, the response to releases coming out in the first month after the end of the reporting period is somewhat stronger than the impact of releases announced in the second month if we compare the percentage of significant coefficients in each month. But on the other hand, the releases in the second month are still significant as a group. Moreover, the releases coming out first do not have the highest impact. Overall, the mere sequence or timeliness of releases cannot explain their relative importance sufficiently.

In contrast, a pairwise comparison of the impact of surprises reveals that the sequence of releases within content categories is important (hypothesis H4). This result suggests that market participants consider various aspects of inflation and economic growth to be relevant in order to determine the equilibrium long-term interest rate. Moreover, it implies that the information value of an additional release for a given month decreases with the number of already available figures providing a similar content. For example, market participants seem to learn enough from the first two housing figures about the strength of demand in that sector so that the subsequently 
released figures have almost no price impact. The only category for which we do not find any significant differences are the three figures providing measurements of past price changes. The exceptional role of inflation rates does not come as a surprise considering the key role of inflation expectations for interest rates. 


\section{A Headline figures in macroeconomic reports}

\begin{tabular}{|c|c|c|c|c|}
\hline Title of Report & $\begin{array}{l}\text { Reporting } \\
\text { Agency }^{a}\end{array}$ & $\begin{array}{l}\text { Headline } \\
\text { Figures }\end{array}$ & Abbr. & $\begin{array}{l}\text { Add. detail } \\
\text { information }\end{array}$ \\
\hline Consumer Confidence & $\mathrm{CB}$ & Consumer confidence index & $C C_{1}$ & \\
\hline NAPM Survey & NAPM & Overall NAPM index & $N A P M_{1}$ & \\
\hline Employment report & BLS & $\begin{array}{l}\text { Non-farm payrolls } \\
\text { Unemployment rate } \\
\text { Averaoe hourly earninoss }\end{array}$ & $\begin{array}{l}E_{1} \\
E_{2} \\
E_{2}\end{array}$ & \\
\hline Producer Prices & BLS & $\begin{array}{l}\text { Overall PPI index } \\
\text { PPI excl. food and energy }\end{array}$ & $\begin{array}{l}P P I_{1} \\
P P I_{2}\end{array}$ & \\
\hline Retail sales & CENS & $\begin{array}{l}\text { Retail sales } \\
\text { RS excl. auto sales }\end{array}$ & $\begin{array}{l}R S_{1} \\
R S_{1}\end{array}$ & \\
\hline Producer Prices & BLS & $\begin{array}{l}\text { Overall CPI index } \\
\text { CPI excl. food and energy }\end{array}$ & $\begin{array}{l}C P I_{1} \\
C P I_{2}\end{array}$ & \\
\hline $\begin{array}{l}\text { Industrial Production } \\
\text { \& Capacity Use }\end{array}$ & FED & $\begin{array}{l}\text { Industrial output } \\
\text { Capacity utilization }\end{array}$ & $\begin{array}{l}I P_{1} \\
I P_{2}\end{array}$ & \\
\hline Housing starts & CENS & Building permits & $H S_{1}$ & \\
\hline Durable orders & CENS & Durable goods orders & $D G O_{1}$ & \\
\hline Employment costs & BLS & Employment cost index & $E C I_{1}$ & \\
\hline Domestic Product & BEA & $\begin{array}{l}\text { Real GDP } \\
\text { GDP deflator }\end{array}$ & $\begin{array}{l}G D P_{1} \\
G D P_{2}\end{array}$ & \\
\hline Personal income & BEA & $\begin{array}{l}\text { Personal income } \\
\text { Consumption expenditures }\end{array}$ & $\begin{array}{l}P I_{1} \\
P I_{2}\end{array}$ & \\
\hline New home sales & CENS & New home sales & $N H S_{1}$ & \\
\hline Leading Indicators & BEA & Index of Leading Indicators & $L I_{1}$ & \\
\hline Construction spending & CENS & Construction spending & $C S_{1}$ & \\
\hline Factory inventories & CENS & $\begin{array}{l}\text { Factory inventories } \\
\text { Factory orders }\end{array}$ & $\begin{array}{l}F I_{1} \\
F I_{2}\end{array}$ & \\
\hline Productivity \& Costs & BEA & Productivity & $P C_{1}$ & \\
\hline Business inventories & CENS & Business inventories & $B I_{1}$ & \\
\hline Trade balance & CENS & Trade deficit & $T R D_{1}$ & \\
\hline
\end{tabular}

Table 1: Content of reports

${ }^{a}$ BEA: Bureau of Economic Analysis, BLS: Bureau of Labor Statistics, CB: Conference Board CENS: Bureau of the Census, FED: Federal Reserve Board, TRES: Department of the Treasury, NAPM: National Association of Purchasing Managers 


\section{B Hypothesized coefficient signs}

\begin{tabular}{|c|c|c|c|c|c|c|}
\hline \multicolumn{2}{|c|}{$\begin{array}{l}\text { Release } \\
\text { Headline } \\
\text { figure } \\
\end{array}$} & $\begin{array}{l}\text { Content of } \\
\text { headline figure }\end{array}$ & $\begin{array}{l}\text { Highe } \\
\text { higher } \\
\text { already } \\
\text { higher } \\
\text { prices } \\
\end{array}$ & $\begin{array}{c}\text { outcomes } \\
\text { iterest rate } \\
\text { higher } \\
\text { consumer } \\
\text { demand }\end{array}$ & $\begin{array}{l}\text { ignal } \\
\text { due to } \\
\text { supply } \\
\text { bottle- } \\
\text { necks }\end{array}$ & $\begin{array}{c}\text { Hypothesized } \\
\text { price } \\
\text { response } \\
\text { of T-Bond } \\
\text { futures }\end{array}$ \\
\hline$C C$ & 1 & Consumer confidence index & & + & & - \\
\hline$N A P M$ & 1 & Overall NAPM index & + & + & + & - \\
\hline$E$ & 1 & Non-farm payrolls & & & + & - \\
\hline & 2 & Unemployment rate & & & - & + \\
\hline$P P I$ & 2 & PPI ex. food and energy & + & & & - \\
\hline$R S$ & 1 & Retail sales & & + & & - \\
\hline$C P I$ & 2 & CPI ex. food and energy & + & & & - \\
\hline$I P$ & 1 & Industrial production & & + & & - \\
\hline & 2 & Capacity utilization & & & + & - \\
\hline$H S$ & 1 & Housing starts & & + & + & - \\
\hline$D G O$ & 1 & Durable goods orders & & + & & - \\
\hline$E C I$ & 1 & Employment cost index & + & & & - \\
\hline$G D P$ & 1 & Real GDP & & + & & - \\
\hline & 2 & GDP deflator & + & & & - \\
\hline$P I$ & 1 & Personal income & & + & & - \\
\hline & 2 & Consumption expenditures & & + & & - \\
\hline NHS & 1 & New home sales & & + & & - \\
\hline$L I$ & 1 & Index of leading indicators & & & & - \\
\hline$C S$ & 1 & Construction spendings & & + & & - \\
\hline$F I$ & 1 & Factory inventories & & & - & + \\
\hline & 2 & Factory orders & & + & & - \\
\hline$P C$ & 1 & Productivity & & & - & + \\
\hline$B I$ & 1 & Business inventories & & & - & + \\
\hline$T R D$ & 1 & Trade deficit & & - & & + \\
\hline
\end{tabular}

Table 2: Hypotheses concerning the reaction of T-Bond futures prices to surprises in macroeconomic headline figures. A " +" ("-") entry indicates a positive (negative) reaction to a higher than expected announcement of individual figures. 


\section{Release cycle}

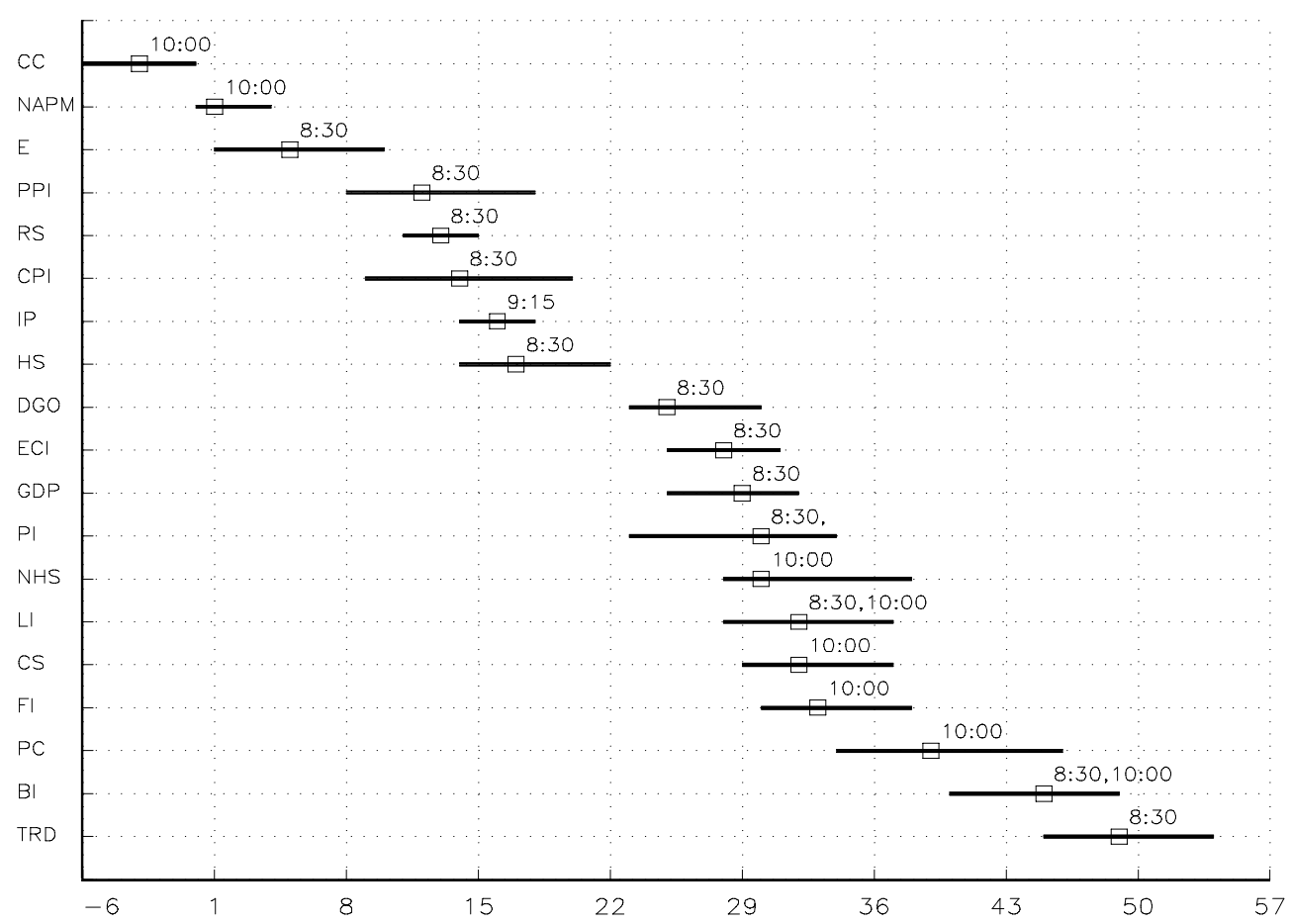

Figure 1: Timeliness of reports: For each report the number of calendar days between the announcement and the end of the reference month is displayed. The median time lag is indicated by a square. A solid line reveals the range between the minimum and maximum number of days. Announcement times are also provided. While most of the reports are released always at the same time, either 8:30 EST, 9:15, or 10:00, the time schedule of $L I$ and $B I$ changes within the sample period, i.e. January 1994 to December 1999. Note that Releases during the government shutdown period in early 1996 are excluded. 


\section{Estimation results}

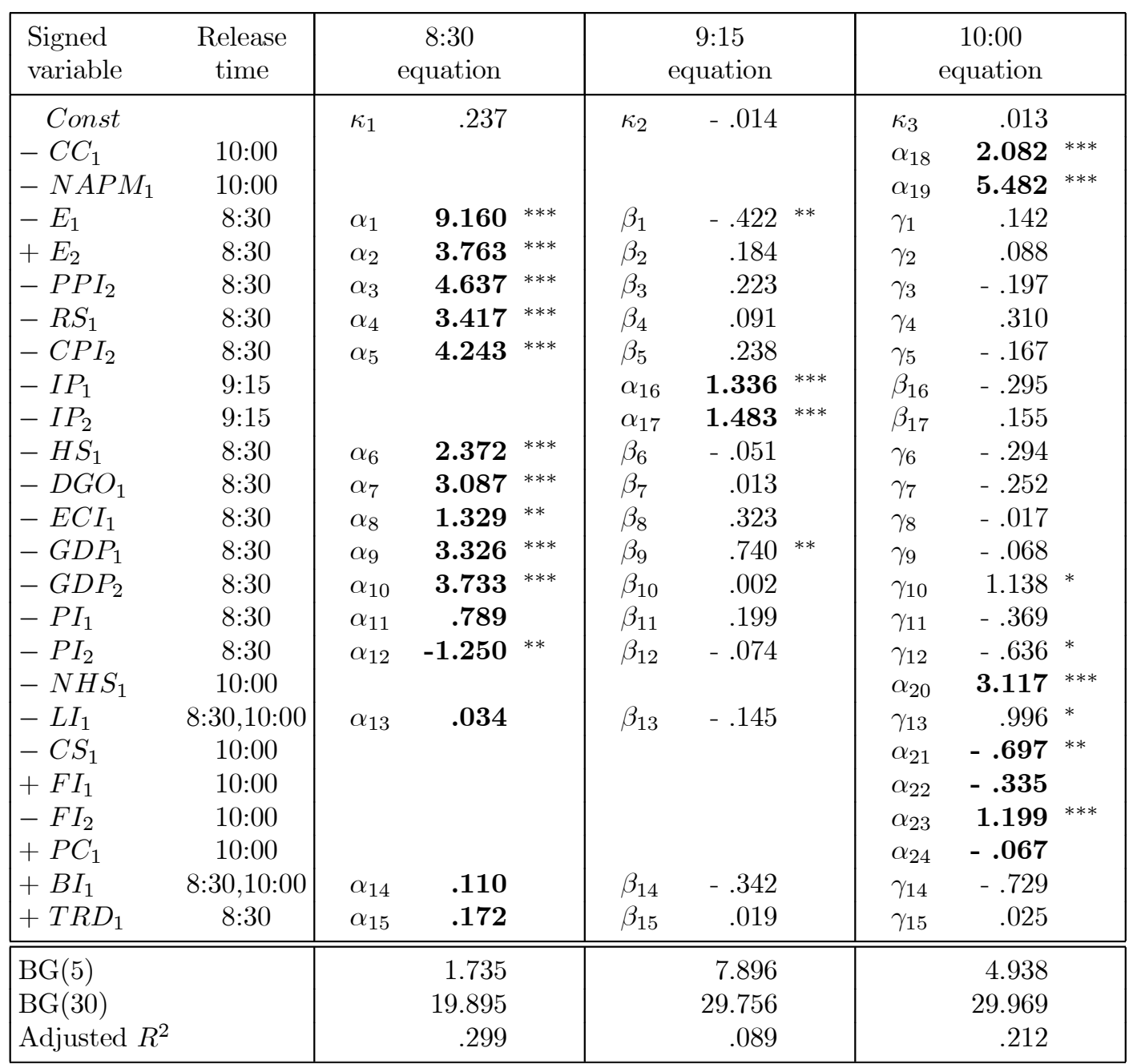

Table 3: Iterative seemingly unrelated regression (SUR) of five minute price changes on standardized surprises (i.e. $S_{t} / E(|A|)$ ). System of three equations, one for each release time, i.e. 8:30, 9:15, and 10:00. Parameters of the system are estimated accounting for heteroskedasticity and contemporaneous correlation in the errors across equations. Significance at the $1 \%$, $5 \%$, and $10 \%$ level is indicated by $* * *, * *$, and $*$, respectively. The sample period is $1 / 94-$ 12/99, including 1497 trading days. Monthly releases are observed 69 each, quarterly 23. BG(n) denotes Breusch-Godfrey test statistics. Since none of these is significant the null hypothesis of zero autocorrelation in residuals up to lag $n$ cannot be rejected. 


\begin{tabular}{lllrrrr}
\hline $\begin{array}{l}\text { Est. Imposed } \\
\text { no. }\end{array}$ & restrictions & $2^{\text {nd }}$ stage & \multicolumn{2}{c}{$\chi^{2}(\nu)$ test on } & d.f. & \\
\hline$(1)$ & $\alpha_{i}=\alpha^{*}, \forall i=1, . .24$ & $\hat{\alpha}^{*}=1.6589$ & 0.0000 & 657.5265 & 23 & 0.0000 \\
$(2)$ & $\beta_{i}=\beta^{*}, \forall i=1, . .17$ & $\hat{\beta}^{*}=0.0291$ & 0.5348 & 16.0335 & 16 & 0.4506 \\
$(3)$ & $\gamma_{i}=\gamma^{*}, \forall i=1, . .14$ & $\hat{\gamma}^{*}=-0.0534$ & 0.4761 & 17.0172 & 13 & 0.2553 \\
\hline
\end{tabular}

Table 4: Asymptotic least squares estimates of restricted parameters. Each line displays the results for a given set of linear restrictions $g\left(\theta^{*}, \hat{\theta}\right)=G \theta^{*}-\hat{\theta}=0$, where $\hat{\theta}$ denotes the $[k \times 1]$ vector of first stage parameters, $\theta^{*}$ the $[q \times 1]$ restricted parameter vector, 0 a $[k \times 1]$ vector of zeros, and $G$ a $[k \times q]$ matrix. The best asymptotic least square estimator of $\theta^{*}$ is obtained by minimizing the quadratic form $\left(G \theta^{*}-\hat{\theta}\right)^{\prime} \hat{\Omega}(\hat{\theta})^{-1}\left(G \theta^{*}-\hat{\theta}\right)$. Parameter tests are constructed from the asymptotic variance-covariance matrix of restricted parameters: $\left(G^{\prime} \hat{\Omega}(\hat{\theta})^{-1} G\right)$, where $\hat{\Omega}(\hat{\theta})$ is the estimated variance-covariance matrix of first stage parameters. A test of the null hypothesis whether the constraints hold, i.e. $G \theta^{*}-\theta=0$, is constructed on the basis of the asymptotically $\chi^{2}(\nu)$ distributed statistic $\xi=\left(G \theta^{*}-\hat{\theta}\right)^{\prime} \hat{\Omega}(\hat{\theta})^{-1}\left(G \theta^{*}-\hat{\theta}\right)$. Here, $\nu=k-q$. For details see e.g., Gourieroux and Monfort 1995, Ch. 9, 18.

\begin{tabular}{llr}
\hline & Parameter restrictions & $\chi^{2}(\nu)$ \\
\hline Economic activity & $\left\{\alpha_{7}, \alpha_{9}, \alpha_{13}, \alpha_{16}, \alpha_{19}, \alpha_{23}\right\}=0$ & $347.84^{* * *}$ \\
C2 (a): & $\left\{\alpha_{4}, \alpha_{12}, \alpha_{13}, \alpha_{14}\right\}=0$ & $87.17^{* * *}$ \\
C2 (b): & $\left\{\alpha_{6}, \alpha_{13}, \alpha_{20}, \alpha_{21}\right\}=0$ & $100.92^{* * *}$ \\
C2 (c): & \\
Inflation expectations & & \\
C3 (a): & $\left\{\alpha_{3}, \alpha_{5}, \alpha_{10}\right\}=0$ & $159.89^{* * *}$ \\
C3 (b): & $\left\{\alpha_{8}, \alpha_{24}\right\}=0$ & $5.54^{*}$ \\
C3 (c): & $\left\{\alpha_{2}, \alpha_{14}, \alpha_{17}, \alpha_{19}, \alpha_{22}\right\}=0$ & $354.49^{* * *}$ \\
Releases with a time lag & & \\
larger than one month & & \\
H3: & $\left\{\alpha_{13}, \alpha_{14}, \alpha_{15}, \alpha_{21}, \alpha_{22}, \alpha_{23}, \alpha_{24}\right\}=0$ & $19.1750^{* * *}$ \\
\hline
\end{tabular}

Table 5: Wald tests on significance of certain groups of parameters. We test whether the $q$ parameters in a given category are zero. The resulting $\chi^{2}(q)$ test statistics are provided. Significance at the $1 \%, 5 \%$, and $10 \%$ level is indicated by $* * *, * *$, and $*$, respectively. 


\begin{tabular}{|c|c|c|c|c|c|c|}
\hline \multicolumn{3}{|c|}{$\begin{array}{c}\text { Overall production } \\
\text { level }\end{array}$} & $\begin{array}{c}\text { Demand for } \\
\text { consumption goods }\end{array}$ & \multicolumn{3}{|c|}{$\begin{array}{l}\text { Demand in } \\
\text { housing sector }\end{array}$} \\
\hline $\begin{array}{l}I P_{1} \\
D G O_{1} \\
G D P_{1} \\
L I_{1} \\
F I_{2} \\
\end{array}$ & $\begin{array}{l}N A P M_{1} \\
4.146^{++}+ \\
2.395^{++} \\
2.156^{++} \\
5.448^{++} \\
4.282^{+++} \\
\end{array}$ & $\begin{array}{c}I P_{1} \\
\\
-1.751^{---} \\
-1.990^{--} \\
1.302^{+++} \\
0.137^{+} \\
\end{array}$ & 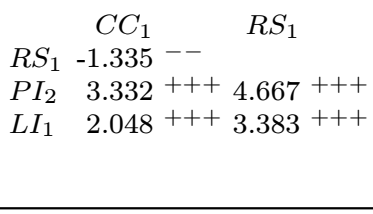 & $\begin{array}{l}N H_{2} \\
L I_{1} \\
C S_{1}\end{array}$ & $\begin{array}{l}H S_{1} \\
-0.744 \\
2.339^{+++} \\
3.070^{+++}\end{array}$ & $\begin{array}{l}N H S_{1} \\
3.083^{+++} \\
3.814^{+++}\end{array}$ \\
\hline \multicolumn{3}{|c|}{$\begin{array}{c}\text { Measures of } \\
\text { past price changes }\end{array}$} & \multirow{2}{*}{$\begin{array}{cc}\begin{array}{c}\text { Early inflation } \\
\text { indicators }\end{array} \\
\\
E C I_{1} \\
P C_{1} & 1.396+\end{array}$} & \multicolumn{3}{|c|}{$\begin{array}{l}\text { Shortage in } \\
\text { production factors }\end{array}$} \\
\hline $\begin{array}{l}C P I_{2} \\
G D P_{2}\end{array}$ & $\begin{array}{r}P P I_{2} \\
0.393 \\
0.903\end{array}$ & $\begin{array}{l}\mathrm{CPI}_{2} \\
0.510\end{array}$ & & $\begin{array}{l}E_{2} \\
I P_{2} \\
F I_{1} \\
B I_{1}\end{array}$ & $\begin{array}{l}N A P M_{1} \\
1.718^{+++} \\
3.998^{+++} \\
5.817^{+++} \\
5.372^{+++}\end{array}$ & $\begin{array}{c}E_{2} \\
2.280^{+++} \\
4.099^{+++} \\
3.653^{+++}\end{array}$ \\
\hline
\end{tabular}

Table 6: Tests on decreasing impact of subsequent releases in individual content categories. We compare the first headline figure with all subsequently released figures in a given content category (left row in each cell). If possible, the same kind of comparison is performed for the second headline figure (right row). Differences between estimated coefficients are displayed for each of the six content categories. A positive entry indicates that the impact of the previously released headline (i.e. the figure given in the top row of a cell) is larger than impact of the report released subsequently (i.e. the figure to the left). A significantly positive (negative) difference according to a one-sided t-test at the $1 \%, 5 \%$, and $10 \%$ level is indicated by ${ }^{+++},{ }^{++}$, and ${ }^{+}\left({ }^{---}\right.$, ${ }^{--}$, and ${ }^{-}$), respectively. Standard errors of the differences are constructed from the estimated variance-covariance matrix. 


\section{References}

Andersen, T. G., And T. Bollerslev (1997): "Intraday Periodicity and Volatility Persistence in Financial Markets," Journal of Empirical Finance, 4, 115-158.

Baltagi, B. H. (1999): Econometrics. Springer, 2nd edn.

Becker, K. G., J. E. Finnerty, and K. J. Kopecky (1996): "Macroeconomic News and the Efficiency of International Bond Futures Markets," Journal of Futures Markets, 16(2), 131-145.

Berkman, N. G. (1978): "On the Significance of Weekly Changes in M1," New England Economic Review, May-June, 5-22.

Bollerslev, T., J. CaI, And F. M. Song (2000): "Intraday periodicity, long memory volatility, and macroeconomic announcement effects in the US Treasury bond market," Journal of Empirical Finance, (7)1, 37-55.

Bureau of Labor Statistics (1996): "Technical Notes to Household Survey Data Published in Employment and Earnings," Office of Employment and Unemployment Statistics, July 30.

Chang, Y., And S. J. TAYlor (1996): "Information Arrivals and Intraday Exchange Rate Volatility," Discussion paper, Lancaster Management School.

Cook, T., And S. Korn (1991): "The Reaction of Interest Rates to the Employment Report: The Role of Policy Anticipations," Economic Review, Federal Reserve Bank of Richmond, 77/5, 3-12. 
Cox, J., J. Ingersoll, And S. Ross (1981): "The Relation between Forward Prices and Futures Prices," Journal of Financial Economics, 9, 321-346.

Crain, S. J., AND J. H. LEE (1995): "Intraday Volatility in Interest Rate and Foreign Exchange Spot and Futures Markets," Journal of Futures Markets, 15, $395-421$.

Dornau, R., And M. Schröder (2000): "Do Forecasters Use Monetary Models? An Empirical Analysis of Exchange Rate Expectations," Discussion Paper 00/12, Center of Finance and Econometrics, University of Konstanz, forthcoming in: Applied Financial Economics.

Dwivedi, T., And K. SRIvastava (1978): "Optimality of least squares in the seemingly unrelated regressions model," Journal of Econometrics, 7, 391-395.

Dwyer, G.-P., And R. W. Hafer (1989): "Interest Rates and Economic Announcements," Review, Federal Reserve Bank of St. Louis, 71/2, 34-46.

Ederington, L. H., And J. H. LeE (1993): "How Markets Process Information: News Releases and Volatility," Journal of Finance, 48, 1161-1191.

EDIson, H. J. (1996): "The Reaction of Exchange Rates and Interest Rates to News Releases," Discussion Paper 570, Board of Governors of the Federal Reserve System.

Fleming, M. J., And E. M. Remolona (1997): "What Moves the Bond Market," Economic Policy Review, Federal Reserve Bank of New York, December, 31-50. 
- (1999a): "Price Formation and Liquidity in the U.S. Treasury Market: The response to public information," Journal of Finance, 54, 1901-1915.

- (1999b): "The Term Structure of Announcement Effects," Discussion paper, Federal Reserve Bank of New York.

Franke, G., AND D. Hess (2000): "The Impact of Scheduled News Announcements on T-Bond and Bund Futures Trading," in Institutional Arrangements for Global Economic Integration, ed. by H.-J. Vosgerau, pp. 337-366, MacMillan, London.

Frumkin, N. (1994): Guide to Economic Indicators. Sharpe, New York, 2nd edn.

Goodhart, C. A. E., And M. O'Hara (1997): "High Frequency Data in Financial Markets: Issues and Applications," Journal of Empirical Finance, 4, 73-114.

Gourieroux, C., And A. Montfort (1995): Statistics and Econometric Models. Cambridge University Press, Cambridge.

Greene, W. H. (1993): Econometric Analysis. Macmillan, New York, 2nd edn.

Hardouvelis, G. A. (1988): "Economic News, Exchange Rates, and Interest Rates," Journal of International Money and Finance, 7, 23-35.

Hemler, M. L. (1990): "The Quality Delivery Option in Treasury Bond Futures Contract," Journal of Finance, 45, 1565-1586.

JARrow, R. A. (1996): Modelling Fixed Income Securities and Interest Rate Options. McGraw Hill.

Mitchell, M. L., And J. H. Mulherin (1994): "The Impact of Public Information on the Stock Market," Journal of Finance, 49, 923-49. 
Niemira, M. P., And G. F. Zukowski (1998): Trading the Fundamentals: The Trader's Guide to Interpreting Economic Indicators and Monetary Policy. McGraw Hill, New York.

PrAG, J. (1994): "The Response of Interest Rates to Unemployment Rate Announcements: Is There a Natural Rate of Unemployment," Journal of Macroeconomics, 16, 171-184.

Rogers, R. M. (1994): Handbook of Key Economic Indicators. McGraw Hill, New York.

Urich, T., And P. Wachtel (1981): "Market Response to the Weekly Money Supply Announcements in the 1970s," Journal of Finance, 36, 1063-1072.

(1984): "The Effects of Inflation and Money Supply Announcemnets on Interest Rates," Journal of Finance, 39, 1177-1188. 